\title{
Tracing pathways to higher education for refugees: the role of virtual support networks and mobile phones for women in refugee camps
}

\section{Citation}

Dahya, N., and Sarah Dryden-Peterson. 2016. Tracing Pathways to Higher Education for Refugees: The Role of Virtual Support Networks and Mobile Phones for Women in Refugee Camps. Comparative Education (December): 1-18.

\section{Published Version}

doi:10.1080/03050068.2016.1259877

\section{Permanent link}

http://nrs.harvard.edu/urn-3:HUL.InstRepos:30195733

\section{Terms of Use}

This article was downloaded from Harvard University's DASH repository, and is made available under the terms and conditions applicable to Open Access Policy Articles, as set forth at http:// nrs.harvard.edu/urn-3:HUL.InstRepos:dash.current.terms-of-use\#OAP

\section{Share Your Story}

The Harvard community has made this article openly available.

Please share how this access benefits you. Submit a story.

\section{Accessibility}




\section{Tracing pathways to higher education for refugees: The role of virtual support networks and mobile phones for women in refugee camps}

\author{
Dr. Negin Dahya \\ University of Washington \\ 015 Mary Gates Hall \\ Box 352840 \\ Seattle, Washington \\ ndahya@uw.edu \\ www.negindahya.com
}

\author{
Dr. Sarah Dryden-Peterson \\ Harvard Graduate School of Education \\ 6 Appian Way \\ Cambridge, MA 02138 \\ sarah dryden-peterson@gse.harvard.edu \\ www.sarahdrydenpeterson.com
}

\section{Acknowledgements:}

We would like to thank many people who have contributed to this work: the young people in Dadaab, Nairobi, and Canada, for participating in this research and sharing your successes and challenges; Windle Trust and UNHCR for facilitating field research in Dadaab; Kenyatta University, in particular Josephine Gitome; the Borderless Higher Education for Refugees project, in particular Wenona Gilles, Don Dippo, Aida Orgocka, and Emily Antze; and Bethany Mulimbi, Sameena Eidoo, Salathiel Ntakirutimana, and Shazia Khan for research assistance.

\section{Funding:}

The study was generously funded by the Weatherhead Center for International Affairs at Harvard University.

Dr. Negin Dahya ${ }^{1}$ is an assistant professor at the University of Washington Information School. Her research examines the social and cultural conditions of technology use in educational settings for refugees, and for underrepresented communities in Canada, USA, and globally. Her work includes understanding the use of digital and mobile technology in refugee education and for girls and women.

Dr. Sarah Dryden-Peterson is an associate professor at the Harvard Graduate School of Education. She leads a research program that focuses on the connections between education and community development, specifically the role that education plays in building peaceful and participatory societies. Her work is situated in conflict and post-conflict settings, particularly with refugee communities. Her research reflects connections between practice, policy, and scholarship and is strengthened through long-term collaborations with Ministries of Education, UN agencies, NGOs, and communities.

\footnotetext{
${ }^{1}$ Corresponding author
} 


\title{
Tracing pathways to higher education for refugees: The role of virtual support networks and mobile phones for women in refugee camps
}

\begin{abstract}
In this paper, we explore the role of online social networks in the cultivation of pathways to higher education for refugees, particularly for women. We compare supports garnered in local and offline settings to those accrued through online social networks and examine the differences between women and men. The paper draws on complementary original data sources, including an online survey of Somali Diaspora $(n=248)$ and in-depth interviews $(n=21)$ with Somali refugees who do or have lived in the Dadaab refugee camps of Kenya. We find an important interplay of local and global interactions, mediated by mobile technology, that participants identify as critical to their access to higher education. Our analysis relates these interactions to shifting social norms and possibilities for refugee women's education. Our findings directly address the use of ICT in expanding opportunities for higher education for women in refugee camps.
\end{abstract}

\section{Keywords}

online social networks, higher education, refugees, mobile technology, gender 


\section{Introduction}

The migratory pathways of refugee contexts are extremely difficult circumstances to navigate. Refugees face geographic change, social isolation, and linguistic and cultural shifts associated with their forced migration. By definition, refugees flee across international borders due to a well-founded fear of persecution (UNHCR 2010), altering their national and transnational support and communication structures. When settling in camps, refugees can be segregated from national populations and have little financial, legal, or educational support. While some refugees are permanently resettled to countries such as the United States, Canada, and Norway, 86 percent live in developing countries neighbouring their countries of origin (UNHCR 2014). Refugees hope that this displacement is temporary and most international aid, including education, is designed based on this assumption. Yet the average duration of exile for refugees is in fact 17 years (Internal Displacement Monitoring Centre 2014). In this state of limbo, refugee children and young people typically have only one shot at education; navigating educational structures to access the limited educational resources available is critical to their success (Dryden-Peterson, 2015).

Technology is creating new and sometimes unexpected opportunities for pathways to education for refugees. This paper offers a discussion of the role of transnational and interregional online social networks over mobile phones, specifically those related to higher education for refugees in camps. We draw comparisons between these mobile online social networks and comparable support structures for teaching and learning within local and offline settings. In this study, we also examine the role of mobile online social networks to create pathways to higher education for refugee women in particular, compared to refugee men, in one patriarchal refugee community. The study draws on theories of development exploring the 
relationship between social and technical structures framing higher education and avenues for refugee women to pursue higher education in camps.

Technology is not a panacea, but research about information and communication technology (ICT) for refugees, ICT for development, and ICT for education (Annan, Taxler, Ofori-Dwumfou 2014; Dahya 2016; Kleine, Hollow, and Poveda 2013; Raftree 2013; Wagner 2014) support the possibility of using ICT to enhance and enable education. The conflict in Syria and resulting refugee crisis has led to a burgeoning, and as yet unconfirmed, belief in the power of technology for refugee education (see, for example, Refugee Ed Tech Solutions and \#EduAppforSyria as just two of many endeavours). Consideration for the role of technology in education is increasingly important in this landscape where online education and mobile technologies are rapidly growing in the developing world and among refugee communities (Ally and Samaka 2013; Dahya 2016). Socio-technical theory emphasises the mutually shaping powers of technology and society, mapping the shifting values and practices that change and connect local and global communities (Latour 2005; Sawyer \& Jarrahi 2014) and that impact transnational structures related to accessing higher education for refugees.

Based on data collected in the Dadaab refugee camps in Kenya, we consider the important role of mobile ICT in the context of refugee immobility. To do so, we focus on Somali refugee women, who are among the most educationally marginalized population groups in the world (see, for example, Buck and Silver 2012; Roy and Roxas 2011). Dadaab is the largest refugee camp complex globally and hosts the largest population of Somalis outside of Somalia (Hammond et al. 2011). In order to identify and understand the types of support structures that can enable success in education, our sample includes Somali refugee women who have graduated from high school. First, we mapped the extent and type of existing naturally occurring online 
social networks and the types of support gained through these networks using an online survey of high school graduates of Somali origin in Diaspora, the majority of whom lived for some time in Dadaab $(n=248)$. Second, through in-depth interviews $(n=21)$, we explored the range of forms of support (e.g., academic, social, emotional) that refugees identify as important to their educational success. In this paper, we present our analysis of the ways in which these forms of support function through online social networks. We find an important interplay of local and global communication that creates educational support mediated and shaped by mobile technology and virtual communication networks. Our findings directly address the use of ICT in expanding opportunities for higher education for women in refugee camps.

\section{Socio-technical theory and pathways to higher education}

In this paper, we draw on a socio-technical perspective to highlight the mutually shaping processes emergent between technology and social practices in the refugee context studied. A socio-technical perspective allows us to consider the way social practices and norms are informed by the integration and use of technology, while the adoption and integration of certain technology are equally influenced by cultural values, expectations, and the social, political, and economic conditions of a particular region (Sawyer \& Jarrahi 2014). In the case of Somali women in the Dadaab refugee camps, a socio-technical perspective and mapping of existing virtual social networks illuminate exceptions to what are otherwise highly restrictive realities with regard to women's opportunities to pursue higher education; it also demonstrates how cultural norms and practices related to women's access to higher education in refugee camps shift through the use of ICT and through their engagement with transnational and online social networks. 
Access to online social networks over mobile phones is not inherently productive. Yet the resources, information, and assistance that accrue through these networks may be (Annan, Taxler \& Ofori-Dwumfou 2014). In Dadaab, refugees are not able to exercise freedom of movement and more than one generation of Somali refugees have lived in the camps with limited access to primary education, let alone secondary and higher education. Women are additionally restricted due to male dominated social expectations controlling their day-to-day activities, requiring them to manage domestic labour and childcare, and due to ongoing sexual violence across the camps (Buck and Silver 2012; Hyndman and Giles 2011). Given the combination of geographically local resources and the way that forced migration scatters refugee communities all over the world, we examine the role of ICT transnationally, in the form of mobile technology.

Research conducted in the Dadaab refugee camps in northeastern Kenya over 15 years ago identified the crucial role of social networks in refugee migration, settlement, and survival (Horst 2002, 2006). Horst (2002) identified the use of radio communication tools across Somali family members in Dadaaab, urban areas of Kenya (Nairobi and Garissa), and across the border in Somalia. At that time, and among those limited technologies available for personal communication, there was already extensive communication across Diaspora, especially with relatives 'to exchange news about their personal situation as well as to send and receive assistance' (245). The movement of information included passing information about family members, communication about business options, goods, and money. The proliferation of the mobile phone has created greater communication possibilities. Given these possibilities, we posit that mobile communication has also expanded the scope of information that moves across borders, including for and about educational aspirations and pursuits.

The type of technology available is an important component of our discussion. In parts of 
Africa, mobile phone usage in particular has grown exponentially over the past decade (Yonazi et al. 2012). The forms of ICT available in any community shape and mediate social engagements. For example, many 'feature phones' - which can access the internet, but lack the capacity of a smartphone - only have access to limited applications. This means that the tools only allow for certain kinds of information seeking practices and communication patterns. Further, how the community chooses to adopt these tools and practices both reflects their own values and culture, as well as impacting how and what users come to know about opportunities, in this case for higher education. It is slow and often expensive to load webpages and access more in depth information on these phones. As such, sharing of information often occurs between people offline, partly due to the cheaper cost compared to internet browsing, and particularly in the context of a society that historically values social support and social networks (Horst 2002). In this paper we discuss how offline practices shift through online text based platforms, and how the structure of wireless and mobile technology in Dadaab is fundamental to the social design of higher education access points in the region. We define agency in relation to the resources (social, material, temporal, etc.) and personal capacities of the individual situated within these larger structures and related to their opportunities to pursue higher education (Kleine 2013).

Like Kleine (2013), we consider the role of technology as part of an ecosystem supporting and also restricting development. Kleine discusses how structural elements influence how local computer access points are organized and impact who uses the services available. This includes the financial structure of the business, library, or community center, the layout of computers and support staff within the space, and the sociocultural norms of the community with regard to gender and education. Agency is enacted within these structures, through resources 
available to community members, and in relation to their personal identifiers such as gender, ethnicity, and age. In Kleine's work, she develops and applies the 'choice framework', to operationalize Sen's capabilities framework, and specifically to understand how structure and agency interact and result in people making choices towards 'the lives they have reason to value' (Kleine 2013). ${ }^{1}$ Kleine argues that what provides individuals with a 'degree of empowerment' is the co-constitutive relationships between structure and agency. Along these lines, we consider how virtual social networks and mobile phones impact perceived and actual avenues for refugee women in camps to pursue higher education. Another way to describe this relationship between structure and agency is to consider individual options, decisions, and actions in relation to existing structures towards desired goals (Attwood \& May 2015).

Technological artifacts are part of these interactive and associative networks of actors. They include devices and other material artifacts that influence, inform, and instigate possibility for choice that result in knowledge-sharing within the undefined structural boundaries of a network. We build on Latour's (2005) focus on the movement, flow, and change ongoing between various actors involved in any relationship, network, or association. Importantly, we narrow in on how the ecological limits of education can change shape through mobile online social network interaction locally and globally.

In a historical context where global communication networks have been only accessible to the elite, access to internet has shifted opportunity structures for youth and less educated people to also engage in transnational social networking. In Ghana, Burrell (2012) documented how spaces like internet cafés 'shaped the yearning for foreign contacts, travel experiences, and an entrenched notion of success as related to one's ties to abroad and to one's global mobility' (7). Such an observation highlights the ways in which virtual networks shift the ecological limits 
of social engagements and related individual identities among communities where access to resources, capital, knowledge, and opportunity are otherwise polarized between rich and poor. Kekwaletswe (2007) posits that the role of social network communities online and using mobile devices in higher education in South Africa can 'be that of an enabling knowledge-sharing space' (105). In a refugee camp context, everyone is economically poor and the gradient between those who have some resources vs. none is moderate but impactful: access to a phone and mobile network may be a key component to the knowledge sharing and social structure that creates higher education pathways in refugee camps.

Contemporary mobile phone based access to internet communication presents altogether different realities of time, space, and possibility in refugee camp contexts compared to less geographically and politically constrained contexts of development. Barriers to space, time, money, and mobility are collapsed in the hand-held, lesser cost, and ready-to-use possibilities of the technological development of the mobile phone. In this study we identify how social realities related to gender and education also change through mobile phone use with regard to accessing higher education. We explore the ways in which social norms and possibilities around higher education for refugees shift with the integration of online social networks over mobile phones. We consider the interactions between structure and agency related to the affordances of the technologies available, including the type of communication that transpires there. The extensive Somali Diaspora in North America and Europe, and the norms about gender and education across these communities in Diaspora, also cross the restricted physical and cultural boundaries of the Dadaab refugee camps over virtual social networks. This makes the offline/online and local/global comparisons pertinent. Understanding how these socio-technical structures effect the 
agency of women compared to men is critical to gender equity initiatives in higher education in refugee settings.

\section{Research context \& methods}

In this paper, our analysis is focused on the following research questions: What is the role of ICT in the pursuit of higher education for Somali refugees in the Dadaab refugee camps? How do ICT support structures influence Somali refugee women's pursuit of higher education? The study included in-depth interviews with refugees from Dadaab pursuing higher education $(\mathrm{n}=21)$ and a survey distributed to Somali Diaspora $(n=248)$. Data was collected in 2013. In this section, we first address the context of education in Dadaab and outline the historical and geographical setting in which this research was conducted before describing our methods of data collection and analysis.

\section{Context: Dadaab camps and higher education}

At the time of data collection, the Dadaab refugee camps in Kenya hosted refugees and asylum seekers, primarily from Somalia, but also from Sudan, Ethiopia, and other parts of Africa (UNHCR 2015). The vast majority refugees in Kenya are Somali, and data from 2016 indicates 321,666 Somali refugees registered in Dadaab (UNHCR, n.d.). Quality of and access to education and educational resources in Dadaab are extremely poor, especially for women (Dryden-Peterson 2011; UNHCR and UNICEF 2011; UNESCO 2012). Figures from 2010, around the time when most of our interview participants graduated high school, indicate that only 28 percent of girls and 72 percent of school-aged boys were enrolled in secondary school in Dadaab (Umbima, Koelbel, and Hassan 2010). Of those who complete high school and sit for the 
national exam, very few perform well enough to apply for university and for the highly competitive university scholarships that make higher education a viable possibility.

Our time in Dadaab and consultations with community leaders highlighted the context of technology access and use for education in the region. In Dadaab, access to technology like computers was limited to recently installed high school computer labs and, for some, to NGO computers in office spaces. Pay-per-use cyber cafés were a part of the camp market economy, but access to these centers was constrained by both cost and safety/security related to transportation, which often entailed unsafe distances by foot, even within each camp region, and especially for women, as also described by Kleine (2013) and Burrell (2012). Currently, some high schools in Dadaab are being fitted with tablets and ICT integrated programming in an attempt to improve education and access to information for teachers and learners (UNHCR 2015b). While these initiatives come with many improvements and successes, ongoing communication with educators and administrators in the region indicate that access to these tools is still limited, connectivity inconsistent, and space still subject to the patriarchal norms of the community. These combined challenges across educational levels make access to higher education sparse.

At the time of this study, there were only three programs that enabled access to higher education degree programs from the Dadaab camps. The World University Scholarship of Canada (WUSC) and the Albert Einstein German Academic Refugee Initiative (DAFI) programs awarded scholarships to 21 female and 53 male students in 2010 (Umbima, Koelbel, and Hassan 2010). Borderless Higher Education for Refugees (BHER) was a new university consortium in 2013 with over 600 applicants for 202 spaces (62 women were admitted); in 2015, 60 students 
completed the Certificate in Educational Studies accredited by York University (Toronto, Canada), approximately 30 percent of whom were women (Dahya 2016).

The availability of technology in Dadaab is an important part of access to education. Second only to radio, much like in other parts of Africa, in Dadaab mobile phones are a key form of communication and means of accessing information for long-term refugee men and women. Social networks are considered a defining characteristic of this community, as social networks, support, and communication have been historically important in Somali society (Horst 2006). Although mobile phone ownership and use is rapidly expanding in Dadaab, in 2011, a mere 20 percent of men and 10 percent of women overall had mobile devices, and only 13 percent of men and 4 percent of women with mobile devices had internet on their phones (Internews 2011). And yet, a survey of students in Dadaab enrolled in higher education $(n=89)$ showed disproportionate mobile phone ownership and internet use compared to the Dadaab population as a whole: 77.5 percent of men and women enrolled in BHER had mobile devices, including 20 out of 26 women (77 percent). Among this student population, use of mobile phones varied from text messaging, to calls with friends and family, with a small proportion using Facebook on internet-enabled mobile devices (27 out of 89, or 30 percent) (Orgocka and Saita 2014).

\section{Methods: participants, data collection and analysis}

We conducted interviews with 21 Somali refugees pursuing higher education who had lived in exile in Kenya. These participants all completed secondary school in Dadaab; at the time of interview, 12 continued to live in Dadaab, 3 lived in Nairobi, and 6 lived in Canada (see Table 1). They were mostly raised in the camps, arriving as toddlers and young children, many without fathers and with mothers without education. All of them were either currently pursuing higher 
education or had been admitted to a higher education program that was to begin imminently. These programs included scholarships from World University Services Canada (those in Canada as well as some awaiting departure from Dadaab), DAFI (those studying in Nairobi), or Borderless Higher Education for Refugees (those remaining in Dadaab). Seven of the 21 interview participants were women. The analysis presented here draws particularly on the data from these in-depth interviews.

[Table 1 about here]

Topics addressed in the in-depth interviews included the general life history of the participant with a focus on educational trajectories and educational supports received and given, current work, future aspirations, transnational connections, technology use, identity, and genderbased experiences. In this way, our study was focused on identifying the support structures and technological factors involved in access to higher education for interview participants. The research is also informed by information we gathered during meetings in Dadaab and in Nairobi with community leaders and agencies working on refugee education in Kenya.

Analysis of interview data was iterative and ongoing. We completed interview notes following each meeting, documenting emerging themes and directions for further exploration. All interview recordings were then transcribed. We created etic codes based on existing literature and emic codes based on themes observed throughout the interviews. Each author then independently coded the same three transcripts, using the qualitative coding software Atlas.ti, adding additional codes as they emerged emically from the data. We discussed any discrepancies until we reached consensus and created our final codebook through this 'collaborative coding' 
process (Smagorinsky 2008). Final code families included 'supports,' 'purpose of education,' 'education system,' 'identity,' and 'work experience.' Our codebook included analytic memos on each code in order to consistently apply codes across interview transcripts and better synthesize our analysis (George and Bennett 2005). We disaggregated the coded content by sex to explore any differences between women and men's narratives about their educational experiences.

We paired the in-depth interviews with an online survey aimed at determining whether and how Somalis living in Diaspora access virtual supports for their education. The survey included questions on types of support, sources of that support, transnational connections, and access to ICTs; most of the questions were closed and a few were open-response. This survey was limited to Somalis who were over the age of 18 and had completed secondary school. We distributed the survey widely to Somali-serving organizations in the United States, Canada, the United Kingdom, Sweden, Ireland, and the United Arab Emirates, as well as through social media groups, Somali-related radio broadcasts, listservs, and personal contacts. We analyze here the 248 surveys that were complete and from unique IP addresses, with a focus on the half of respondents who had lived in a refugee camp at one time (70 percent of whom lived in Dadaab) and the 36 percent of all surveys from women. The development and implementation of the survey is described in detail in [Authors, under review]. Analysis of the survey results was conducted using STATA 13 and, for this paper, focused on analysis of difference by sex as well as by the type of virtual supports prioritized by the participant. These survey responses from Diaspora members are important components of the larger educational support structure for refugees in Dadaab, representing the profile of people with whom interview participants in Dadaab communicate, which we identified in the in-depth interviews. 


\section{Findings}

\section{Socio-technical conditions for educational change}

Ladan explained that the cultural practice of female genital mutilation in the camps was a major hindrance to girls' education due to the physical pain and health complications it caused. She indicated having little support to address these challenges besides that of her mother as she persisted through primary and secondary schooling. She also said that she rarely used the internet or computer technology. Ladan did explain, however, that she communicated regularly with and sought support from former classmates living outside of Dadaab and in other areas of the camps using instant messaging on her mobile phone. She used the mobile phone applications WhatsApp Messenger and Nimbuzz ${ }^{2}$ to communicate with friends and family about her educational pursuits.

Ladan did not perceive broadband-based communication using instant messaging as a form of either internet or computer technology. For Ladan, communication on mobile devices and the social networks there were completely intertwined in such a way that for her, the presence of the technology was secondary to the social support and communication exchanged between women over these communication channels. The invisibility of the role of the technology in mediating and mitigating these communications is important. When investigating the role of technology in the lives of these refugee women, they described technology as 'not relevant' despite unanimous articulations of the crucial social role of the networks facilitated by these ICT tools. This use of mobile and networked communication structures describes a sociotechnical condition that fundamentally changes the structure of education in the camps: the mobile online social network extends support to outside of the camps and directly impacts what 
Kleine (2013) calls 'degrees of empowerment' - existence of choice, sense of choice, use of choice, achievement of choice, to pursue higher education through ICT.

For women in Dadaab, ‘technology' conjured conceptualizations of hardware, computers, and internet cafés, few of which were described as available or as support structures for these research participants. The constructs of international aid and development initiatives to raise money for technology programs often positions people (men and women) living in developing regions as unskilled, a type of global representation of African/Africans that is distributed virtually and might also impact how locals see themselves within the larger world of technology, representing an oversimplified 'dichotomy between users and nonusers' (Burrell 2012, 9). In this case, only two of the women we interviewed indicated 'technology' as something they had any experience with or that contributed as a support to their success in education, and these were both women already living outside of refugee camps with access to a wider range of technological resources on Canadian university campuses.

Mobile technology and online social networks, however, were used with great frequency and effect, not discussed as 'technology' but rather as part of the peer-to-peer support structures that were relevant to all interview participants in their pursuit of higher education. In this way, the integration of social and technical conditions reconfigured opportunities for refugee women to pursue higher education. The ways in which refugee women perceived themselves as technology users will be revisited throughout subsequent sections of this paper.

\section{ICT and access to information about higher education for refugee women}

Refugee women absorbed mobile technologies into the social and cultural norms of their community; at the same time, design, infrastructure, and functionality of the tools also influenced 
social and cultural values and behaviours. Kleine (2013) positions 'technological structure' and 'educational resources' as interactive factors related to individual agency. We propose that these factors are interactive and, in this case, entirely intertwined; one might not proliferate without the other, in this context, under the restrictions for refugee women in camps. Such a purview suggests that structure and agency - technology as well as educational, social, and cultural resources - not only create conditions for education, but influence and shape culture and society. Not only is technology an important and co-constitutive element of individual structure and agency, it is also part of a socio-technical sphere that can change the form and opacity of the ecological boundaries of the education structure in a refugee camp: the ecological limits of the educational sphere are permeable; the boundaries shifting across physical and virtual spaces wherein educational choices are made.

Indeed, to create these social networks, interview participants drew on a collection of technological supports situated across local and global contexts. Facebook was the primary means of communicating with peers and used by most of the interview participants, whether they lived in Canada, Nairobi, or Dadaab. Hogol confirmed that Facebook on her mobile phone was the primary means of communication for her with friends and family in Dadaab while she was in Canada. Haboon said, ‘ ... actually, I didn’t have a Facebook account when I was in secondary. I made it when I graduated from secondary...[Then, when I was in Dadaab], I used to communicate to the students here in Canada who also got scholarship before us, so I used to ask them what they are doing, what their ambition is, how they are finding school.'

Many of our participants indicated not having access to Facebook or mobile phones until after completing secondary school, which usually coincided with acquiring incentive work ${ }^{3}$ to pay for a device, adding monetary resources to this complex structure. The use of technology 
demonstrates divides between secondary and post-secondary education that exist in the social and economic structure of the camps. The goals and outcomes of achieving higher education are defined in relation to local and global information about higher education that permeate the social walls of the camp. Individuals and communities within the camps can then transfer information into locally relevant knowledge that is 'intertwined with the social settings in which it is encountered' (Kekwaletswe 2007, 106).

For example, Kahaa communicated regularly with friends and family on Facebook to discuss school, education, and 'life' more generally. Facebook was a way for her to connect outside of the Dadaab camps and, at the same time, she indicated that her online communication with peers already enrolled in post-secondary programs in Nairobi and abroad kept her informed about new programs and opportunities in the camps, including Borderless Higher Education for Refugees to which she had recently applied. Communication with peers outside the camps informed Kahaa's understanding of her own life and current events within and surrounding the camps.

Kahaa explained that the content of her communication with these peers - with whom she had graduated secondary school - was to ask about their experiences in post-secondary education and how they managed to succeed in securing scholarships to attend university overseas. Mandeeq explained that her Facebook friends - who were also from Dadaab - offered a good place to share histories and provide support towards pursuing higher education. Mandeeq indicated also communicating with refugee men from Dadaab who were in Canada on the WUSC scholarship regularly to share ideas. They too, she indicated, were supportive - a dynamic between men and women limited to very controlled school spaces, which are sometimes less available following completion of high school. The information accrued through these 
networks provided access to valuable and sometimes necessary information that set the foundation for pursuing higher education.

\section{Online and offline social supports for refugee women}

The relationship between social support structures surrounding higher education for refugees and refugee women's sense of agency to pursue higher education is clearly influenced by integrated social and technical interactions in this study. Among male and female survey respondents ( $\mathrm{n}=248), 45$ percent received academic support through virtual channels. This support came in the form of guidance, tutoring, writing support, exam preparation, and course selection. Interestingly, 69 percent of these respondents noted that their virtual academic support was initially locally situated, indicating the likelihood of virtual connections building from preexisting face-to-face relationships (Authors, under review). Female respondents who lived in refugee camps used Facebook for social support towards their education (33 percent), though far less than their male counterparts (63 percent) (see Table 2). The local creation of virtual support was magnified for women, with 81 percent responding that their virtual connections were based on face-to-face relationships. The extension of these face-to-face relationships was crucial to continued pursuit of higher education for refugee women as well as for men.

[Table 2 about here]

Refugee women identified the short-fall of female teachers in Dadaab as a clear lack of locally situated academic support, making global support more urgent. Hogol, now studying at a university in Canada, described how she became a role model in the community after receiving the WUSC scholarship. She said, 'because they [teachers] were all male, so there was no female 
teaching there, so they [men] asked me to come over and tell them [the girls, about education]. They were like, 'If we talk to them, they will not be motivated. But if they see a girl the same status, the same age going to universities in Canada, they will be a little encouraged to do hard work and to raise that goal.' Female survey respondents living in refugee camps received virtual social support overwhelmingly from student peers whereas male respondents relied on friends, family members, and teachers. This distinction between what is a lack of social support for education for women in the camps compared to available support through virtual connections emerges clearly in interview responses. Studies working in health and education similarly show how international, online social networks can enhance education when focused on shared professional development goals (Pimmer, Linxen \& Grohbiel 2012).

Female respondents, particularly those who lived in refugee camps, overwhelmingly Dadaab, relied heavily on student peers for virtual academic support (69 percent), whereas men relied more heavily on teachers for virtual academic support (56 percent). For men, many of these teachers were also considered friends, given that students will often graduate high school and in the following year start working as high school teachers.

Both refugee men and women interviewed identified various types of social support that they attributed as critical to their educational success, including the support of their mothers. Seventy-five percent of women who had lived in refugee camps also relied on telephone for academic support. This highlights the multiplicity of use of mobile telephony to mediate support structures and specifically to create role model networks among refugee women in camps. All of the refugee women interviewed indicated that they served as role models for other girls in their local community and most women interviewed indicated that they had female role models locally and globally who encouraged them to continue their education. We define role models as 
individuals with whom regular communication and ongoing relationships inform, support, and inspire respondents throughout their education. Women emphasized the importance of both having and being a role model more than did men.

Hogol described how she maintained relationships with other women from the camps when they received scholarships and went to Canada to pursue higher education. As a scholarship holder herself, she continued to receive requests and give academic writing support to these peers online and by phone. Similarly, Haboon explained, ‘...I felt like I have to help my fellow sister, my fellow women...I'll become a role model for them... when a man motivates them, they can say, "This is a man who cannot do as we did. He doesn't have our challenges"'. While survey respondents living in Diaspora prioritized social support using mobile phones, interview participants complicate the notion of 'social' showing how academic support is embedded in these social networks for refugee women in Dadaab. The socio-technical relationships emergent in these networks has important implications for gender equity within the educational landscape of the Dadaab refugee camps.

\section{Gender(ed) pathways}

Male and female interview participants used technology and support structures in different ways in their educational pursuits. For instance, while most interview participants indicated that they had some access to internet communication and information online, mostly through mobile phones, all of the female participants indicated that this online information and support came in the form of online social networks. This finding aligned with survey responses. Male participants indicated having more opportunities to search the web, read the news, and listen to radio broadcasts online than female participants, and these were also seen as ways of 
seeking and accessing educational support online. This difference was locally situated in men's greater access to computers in employment positions in the camps, access to computers at university outside of the camps, and due to the reality of male participants having more leisure time for this type of activity while women prepared meals and cleaned the home in the early morning and evening.

These various examples of how refugee women used technology, and how they perceived themselves as technology users (or not), reflects two important socio-technical realities that are prevalent across developed and developing regions related to the masculine culture of technology. The masculine culture of technology is described by Wajcman $(1991,2004)$ and others (Iwilade, 2015; Masika and Bailur 2015) as a socially constructed division of gender positioning technology as the domain of men, and sometimes functioning as a tool for further control of women (Masika and Bailure 2015). Such a position regarding gender and technology in development includes men controlling women's use of technology and women's technology training being deprioritized compared to men's - a problem that is often more extreme in conflict and crisis settings (Dahya 2016; Lewis and Lockheed 2007; UNESCO 2011).

The role of mobile online social networks in ongoing efforts for gender equity is then twofold in this study. First, mobile phones can be put in the hands of women directly and their use of the phones is more in their control, with possibilities for more access and privacy in those communications than in internet café or computer lab settings. However, 'empowerment' through ICT for women is not a given. Masika and Bailur (2015) discuss women's 'situated agency' in development considering how resources like mobile phones are carefully leveraged by women in ways that negotiate their lived experiences as subjects within patriarchal homes and societies. In a study focused on women's use of mobile phones in Uganda, Masika and Bailur 
identified how a mobile phone might be used for business or work during the day and actively not used at night to avoid conflict with male family members enacting misogyny and presuming communications are nefarious (Masika \& Bailur 2015). Second, the gendered culture of technology literacy and use that can permeate social relations across patriarchal communities results in complex and layered challenges to acquiring literacy of machines and software needed to access information about higher education (see Iwilade 2015); the naturally occurring social relationships that motivate mobile technology use, and personalized access of the tool, may mitigate some of these challenges for refugee women seeking information about pathways to higher education in camps.

\section{Discussion: mobile phones, women's agency and higher education in refugee camps}

Refugee women are burdened with social expectations related to domestic labour and child-care, persistent inequalities that become heightened in the face of armed conflict and forced migration (Dahya 2016; Lewis and Lockheed 2007; UNESCO 2011). We demonstrate that online social networks both interrupt inequitable social and economic norms in the physical and geopolitical world of Dadaab, and create opportunities for some women to pursue higher education within refugee camps. In our study, online social networks accessed using mobile phones have changed the social and educational landscape of higher education for our interview participants. Such change creates opportunities for people to 'choose the life they value' (Kleine 2013) by redefining the social and cultural structures they are required to navigate.

Kleine (2013) defines technologies of choice as technologies that offer people opportunities to make choices that matter to them. Internet enabled mobile phones offer unique possibilities for access to information about higher education through social networks for refugee 
women in Dadaab. In our study, mobile phones and online social networks mediated choices and values towards the pursuit of higher education in an instrumental way by shaping and shifting social and cultural norms related to the possibility of educational pathways for these refugee women. The nature of communication exchange possible on these devices and with the infrastructure in place allowed transnational discussions over text-based communication to transpire and have a significant impact on refugee women's access to higher education; such a network comprised of technological and human actors (Latour 2005), contributing to the changing cultural values and social allowances for more women to break boundaries and pursue higher education against the odds - if only a few a time.

Mobile social networks, mediated through social networking sites like Facebook, but also instant messaging platforms like WhatsApp and aggregating tools like Nimbuzz, are impacting access to higher education for refugees in unexpected ways. Through these transnational networks, the participants in this study garnered information about 'what it's like' for refugees and for women to study in post-secondary institutions. Importantly, these networks were with peers from Dadaab either in Dadaab, Nairobi, or Canada studying at the higher education level. This extension of local social support structures was crucial to the success of interview participants in their higher education pursuits. In part, this is due to the structure of higher education scholarships that remove those individuals from the camps to other locations. However, as more local and online opportunities to pursue higher education from within Dadaab emerge, the role of these communication networks persisted precisely because of the importance of social networks to this community (Horst 2002, 2006), and due to the limitations to mobility locally that define many refugee camp contexts. Accessibility of mobile technologies and the online social networks they facilitate can change not only individual communication networks 
but the larger social and cultural norms and values that circulate, constrict, and transform refugee camp contexts.

\section{Conclusion}

The experiences of the women interviewed for this study echo the broader survey and suggest that support and communication over mobile phones and online social networks are important in generating educational opportunities for refugees. In-person, peer-to-peer support was also extremely important, though displacement, resettlement, or temporary schooling outside of the camps underscored the persistent value of online connections. All of the women interviewed for this study had access to a mobile phone and had engaged with the larger structure of transnational social networks online. Access to the mobile phone, with the resources to connect it to the internet, having networks online (social resources), and the knowledge of how to use those platforms intersected and influenced their ability to seek out pathways to higher education (enacting their agency). Their networks comprised of people they knew from the camps and continued to engage with after their migration from Dadaab to Nairobi or Canada, and these networks were notably important to their educational endeavours. This was also true for men, though men also had greater access to resources ranging from computers to male teachers/role models locally, and more time to study and engage in person peer-to-peer support.

Despite ongoing initiatives to improve education and access to higher education in Dadaab, since 2013 insecurity in the region has made life and education there additionally challenging. Ongoing violence has included Kenya sending troops to Somalia to combat AlShabab (Gathara 2015), and Al-Shabab terror attacks in Nairobi at Westgate Mall in 2013 (Gathara 2015; Mcconnell 2015) and at Garissa University in 2015 (Gathara 2015; BBC 2015), 
all of which have generated a climate of fear among refugees in Kenya. In 2016, the Kenyan government announced, not for the first time, its intentions to close the Dadaab camps due to this ongoing violence in the region and conflict between Kenya and the militant extremist group from Somalia, Al-Shabab. Attacks on education specifically demonstrate how efforts to pursue higher education can be political (Dryden-Peterson, Dahya \& Giles 2013a, 2013b), especially for women. Our participants shared how women's bodies are the target of misogyny in Dadaab (as elsewhere) where walking alone to get fire wood or outside of normative daytime hours can result in sexual assault, making school-going for girls and women additionally difficult. The climate in Kenya has worsened to the extent that, since the tripartite agreement between Somalia, Kenya, and UNHCR in 2015, ${ }^{4}$ and following the Kenyan governments 2016 threat to close the camps, Somalis in Dadaab are considering in far greater numbers a return to Somalia despite ongoing conflict and incomplete infrastructure and governance there (Al-Jazeera 2016; UNHCR 2016). On-going conflict and displacement additionally point to the need for understanding network flows of information, culture, and support, mapping pathways to higher education for these refugees as their forced migration continues.

Refugee education is marked by ongoing conflict, violence and war, by mass forced migration resulting in little to no infrastructure or resources for refugees, including trained teachers, school buildings, and established educational curriculum and support. Family and friends are separated along the way to exile and over time as individuals and family-units are relocated while others remain in urban or camp-based settings. In the contemporary world of mobile technology and social network sites, communication practices are changing and education-related activities are finding new pathways for transmission. Across this technological landscape, the role of transnational connections to support refugee education stands to be better 
understood. This is uniquely so at the level of higher education and for refugee women where, as presented in this paper, technology and social networks are emerging as part of an important pathway to increased access to and persistence in higher education in refugee camp contexts. 


\section{References}

Ally, Mohamed, and Mohammed Samaka. 2013. "Open Education resources and mobile technology to narrow the learning divide." The International Review of Research in Open and Distance Learning 14 (2).

Al Jazeera Staff. 2016. Kenya's plan to shut Dadaab refugee camp criticized.

http://www.aljazeera.com/news/2016/06/dadaab-refugee-camp-somalia-diplomat-opposes$\underline{\text { closure-160603051614121.html }}$

Annan, N.K., J. Traxler, and G. Ofori-Dwumfou, 2015. "Mobile communication for the development of education: a developing country's perspective." In I.N.C Scharff and C. Wamala (Eds.) Proceedings of $4^{\text {th }}$ International Conference on M4D Mobile Communication for Development. http://www.divaportal.org/smash/get/diva2:709233/FULLTEXT03.pdf\#page=146

Attwood, E.H. and J.D. May. 2015. "Fine-tuning Kleine's choice framework." Published in ICTD 2015 Proceedings of the Seventh International Conference on Information and Communication Technologies and Development, Article 25. New York: ACM.

BBC News. 2015. Kenya attack: 147 dead in Garissa University assault. http://www.bbc.com/news/world-africa-32169080

Buck, Patti, and Rachel Silver. 2012. Educated for change?: Muslim refugee women in the west. Charlotte, N.C.: Information Age Pub.

Burrell, Jenna. 2012. Invisible Users: Youth in the Internet Cafés of Urban Ghana. Cambridge: MIT Press.

Dahya, Negin. 2016. Education in Conflict and Crisis: How Can Technology Make a Difference? A Landscape Review. Published by GIZ, USAID, WVI. Germany. http://www.ineesite.org/en/resources/landscape-review-education-in-conflict-and-crisis-howcan-technology-make-a

Dryden-Peterson, Sarah. 2011. "Refugee Education: A Global Review." Geneva: UNHCR. http://www.unhcr.org/research/evalreports/4fe317589/refugee-education-global-review-sarahdryden-peterson-november-2011.html

Dryden-Peterson, Sarah. 2015. "Refugee education in countries of first asylum: Breaking open the black box of pre-resettlement experiences." Theory and Research in Education: 1-18.

Dryden-Peterson, Sarah., N. Dahya, and W. Giles. 2013a. "Education: A Challenge to Terror." Op-Ed in The Globe and Mail published October 3, 2013.

http://www.theglobeandmail.com/news/national/education/can-education-be-a-challenge-toterror/article14663419/ 
Dryden-Peterson, S., Dahya, N., and Giles, W. 2013b. "Education: A Challenge to Terror." OpEd in The Huffington Post published September 30, 2013. http://www.huffingtonpost.com/sarahdrydenpeterson/education-a-challenge-to- b 4018869.html

Gathara, Patrick. 2015. Is Kenya at war with Al-Shabab? AlJazeera.

http://www.aljazeera.com/indepth/opinion/2015/04/kenya-war-al-shabab$\underline{150414111433725 . h t m l}$

George, A.L. and A. Bennett 2005. "Integrating comparative and within-case analysis: Typology theory." In Case Studies and Theory Development in the Social Sciences, 263-285. Cambridge: MIT Press.

Hammond, Laura, Awad Mustafa, A.I. Dagane, Peter Hansen, Cindy Horst, Ken Menkhaus and Lynette Obare. 2011. "Cash and Compassion: The role of the Somali Diaspora in Relief, Development and Peace-building." New York: UNDP.

Horst, Cindy. 2002. "Vital links in social security: Somali refugees in the Dadaab camps, Kenya." Refugee Survey Quarterly, $21(1 \& 2)$, p. 242-260

Horst, Cindy. 2006. Transnational nomads: how Somalis cope with refugee life in the Dadaab camps of Kenya. New York: Bergham.

Hyndman, Jennifer, and Wenona Giles. 2011. "Waiting for what? The feminization of asylum in protracted situations." Gender, Place \& Culture: A Journal of Feminist Geography 18(3):36179.

Internal Displacement Monitoring Centre. 2014. Global Estimates 2014: People displaced by disasters. Geneva: Internal Displacement Monitoring Centre.

Internews. 2011. Dadaab, Kenya. Humanitarian communications and information needs assessment among refugees in the camps: findings, analysis \& recommendations. .

Iwilade, Akin. 2015. New spaces, new interactions? Young people's online social networks and gender relations in Africa. Gender, Technology and Development, 19(1), 70-90. DOI: $10.1177 / 0971852414561613$

Kleine, Dorothea. 2013. Technologies of Choice? ICTs, Development and The Capabilities Approach. Cambridge: MIT Press.

Kleine, Dorothea, David Hollow and Sammia Poveda. 2013. Children, ICT and Development: Capturing the Potential and Meeting the Challenges. New York: UNICEF. https://www.unicefirc.org/publications/pdf/unicef royalholloway ict4dreport final.pdf 
Kekwaletswe, R.M. 2007. Social presence awareness for knowledge transformation in a mobile learning environment. International Journal of Education and Development using Information and Communication Technology, 3(4), 102-109.

Latour, Bruno. 2005. Reassembling the Social: An Introduction to Actor-Network-Theory. Oxford: Oxford University Press.

Lewis, Maureen. And Marlaine Lockheed. 2007. "Social exclusion: The emerging challenge in girls' education." In Exclusion, Gender and Education: Case Studies from the Developing World, edited by Maureen Lewis and Marlaine Lockheed. Washington, DC: Center for Global Development.

Mcconnell, Tristan. 2015. 'Close your eyes and pretend to be dead': What really happened two years ago in the bloody attack on Nairobi’s Westgate Mall. Foreign Policy http://foreignpolicy.com/2015/09/20/nairobi-kenya-westgate-mall-attack-al-shabab/

Orgocka, Aida., and K. Saita. 2014. Borderless Higher Education for Refugees: Use of mobile devices among BHER students. Draft report. Toronto: York University.

Masika, Rachel. and Savita Bailur. 2015. "Negotiating women's agency through ICTs: a comparative study of Uganda and India." Gender, Technology and Development, 19(1), 43-69. DOI: $10.1177 / 0971852414561615$

Perouse de Montclos, M-A. and P.M. Kagwanja. 2000. "Refugee camps or cities? The socioeconomic dynamics of the Dadaab and Kakuma camps in Northern Kenya." Journal of Refugee Studies, 13(2), 205-222.

Pimmer, Christopher, Sebastian Linxen, and Urs Grohbiel. 2012. "Facebook as a learning tool? A case study on the appropriation of social network sites from mobile phones in developing countries." British Journal of Educational Technology 43 (5):726-738.

Raftree, Linda. 2013. Landscape Review: Mobiles for Youth Workforce Development. Washington, DC: Aguirre Division of JBS International for The Mastercard Foundation. http://www.youtheconomicopportunities.org/sites/default/files/uploads/resource/mywd landscap e review final2013 0.pdf

Roy, L. A., and K.C. Roxas. 2011. "Whose Deficit Is This Anyhow? Exploring Counter-Stories of Somali Bantu Refugees' Experiences in 'Doing School'". Harvard Educational Review, 81(3), 521-541. 
Sawyer, Steve and Mohammad Jarrahi. 2014. "The Sociotechnical Perspective," in A. Tucker and H. Topi (Ed), 5(1), 5-27. CRC Handbook of Computing. New York: Chapman and Hall.

Smagorinsky, Peter. 2008. "The Method Section as Conceptual Epicenter in Constructing Social Science Research Reports." Written Communication 25 (3):389-411.

Umbima, J., Koelbel, A. and Hassan, A.A. 2010. Joint Review and Assessment of the Education Sector in Dadaab Refugee Camps. Nairobi: UNHCR.

UNESCO. 2011. Education for All Global Monitoring Report 2011: The hidden crisis: Armed conflict and education. Paris: UNESCO.

UNESCO. 2012. World atlas of gender equality in education. Paris: UNESCO.

UNHCR. 2010. Convention and Protocol Relating to the Status of Refugees Geneva: UNHCR.

UNHRC, n.d. Refugees in the Horn of Africa: Somali Displacement Crisis.

http://data.unher.org/horn-of-africa/region.php?id=3\&country=110

UNHCR. 2014. UNHCR Global Trends 2013: War's Human Cost. Retrieved from Geneva: http://www.unhcr.org/cgibin/texis/vtx/home/opendocPDFViewer.html?docid=5399a14f9\&query=global trends 2014

UNHCR. 2015. "Kenya Fact Sheet, March 2015." http://www.unhcr.org/524d84b99.html.

UNHCR. 2015b. "Instant Network Schools: Leveraging mobile technology to improve the quality of education provided for refugees. http://innovation.unhcr.org/labs post/instantnetwork-schools/

UNHCR. 2016. Joint Communiqué: Ministerial Tripartite Commission for the Voluntary Repatriation of Somali Refugees from Kenya to Somalia. http://www.unhcr.org/enus/news/press/2016/6/576ea0474/joint-communique-ministerial-tripartite-commission-voluntaryrepatriation.html

UNHCR, and UNICEF. 2011. Joint Strategy for Education in Dadaab, 2012-2015. Dadaab, Kenya: UNHCR, UNICEF, CARE, Windle Trust, Avsi, ADEO, NRC, National Council of Churches Kenya, Save the Children, Handicap International, GiZ, FilmAid.

Wagner, D.A. 2014. Mobiles for reading: a landscape research review. Washington, DC: USAID and mEducation Alliance.

http://literacy.org/sites/literacy.org/files/publications/wagner mobiles4reading usaid june 14.p $\underline{\mathrm{df}}$ 
Wajcman, Judy. 1991. Feminism Confronts Technology. Oxford: Polity Press.

Wajcman, Judy. 2004. TechnoFeminism. Malden: Polity Press.

Yonazi, Enock, Tim Kelly, Naomi Halewood, and Colin Blackman, eds. 2012. The

Transformational Use of Information and Communicaton Technologies in Africa. Washington, DC: World Bank, African Development Bank, African Union. 
Table 1. Characteristics of Interview Participants $(n=21)$

\begin{tabular}{l|c|c|c|c|c|c|c}
\hline & $\begin{array}{c}\text { Country } \\
\text { of } \\
\text { origin }\end{array}$ & $\begin{array}{c}\text { Location of } \\
\text { Primary/ Secondary } \\
\text { Education }\end{array}$ & \multicolumn{2}{|c|}{ Current location } & \multicolumn{2}{|c}{ Level of education } \\
\hline & Somalia & Dadaab & Dadaab & Nairobi & Canada & $\begin{array}{c}\text { Secondary } \\
\text { school }\end{array}$ & $\begin{array}{c}\text { Some } \\
\text { higher } \\
\text { education }\end{array}$ \\
Male & 14 & 14 & 8 & 3 & 3 & 8 & 6 \\
Female & 7 & 7 & 4 & 0 & 3 & 4 & 3 \\
\hline
\end{tabular}

Table 2. Dimensions of Virtual Support for Somali Diaspora members who lived in refugee camps (see also Authors, under review)

\begin{tabular}{l|c|c|c|c}
\hline & \multicolumn{2}{|c|}{ Academic support (n=87) } & \multicolumn{2}{c}{ Social support (n=39) } \\
Sources of virtual support & Men & Women & Men & Women \\
Teachers & $56 \%$ & $44 \%$ & $44 \%$ & $33 \%$ \\
Family & $25 \%$ & $13 \%$ & $56 \%$ & $33 \%$ \\
Friends & $36 \%$ & $50 \%$ & $75 \%$ & $33 \%$ \\
Student peers & $42 \%$ & $69 \%$ & $44 \%$ & $67 \%$ \\
\hline Mechanisms of Virtual Support & & & & \\
Email & $61 \%$ & $56 \%$ & $56 \%$ & $100 \%$ \\
Phone & $56 \%$ & $75 \%$ & $94 \%$ & $100 \%$ \\
Text messaging & $36 \%$ & $19 \%$ & $56 \%$ & $100 \%$ \\
Facebook & $25 \%$ & $6 \%$ & $63 \%$ & $33 \%$ \\
Discussion boards & $22 \%$ & $31 \%$ & $13 \%$ & $0 \%$ \\
\hline
\end{tabular}

\footnotetext{
${ }^{1}$ Dorothea Kleine's (2013) choice framework is designed to operationalize and apply Amartya Sen's Capabilities Approach (1999) to ICT for Development studies (ICTD). The choice framework is comprised of four primary sections: structure and agency which are co-constitutive, degrees of empowerment pertaining to the existence of choice, sense of choice, use of choice, and achievement of choice of an individual or community, and development outcomes or achieved functionings within an ecological system. The premise of the framework is to maintain Sen's core principles for economic development focused on expanding individual freedoms and pursuing avenues that allow people in developing settings 'to live the lives they have reason to value.' Kleine applies the choice framework to several case studies in Algun, Chile, where she explores how the different elements of the framework (structure, agency, choice, outcomes) interact towards achieving or failing to achieve development goals. Kleine complicates the notion of choice within variable and interrelated structures (such as institutional structure, discourse, policies, technologies, social norms, and law); she positions these structures as coconstituted by agency, which is itself related to the different personal and external resources available to an individual and within a community. Through this framework, Kleine offers nuanced discussions about ICT for development maintaining the desired goals and outcomes of the individual or community at the
} 
center. We explore the relationship between structure and agency throughout this paper, and touch on degrees of empowerment and outcomes where they are visible.

${ }^{2}$ What's App is a free internet-based application for instant messaging. Nimbuzz is a cross-platform application for mobiles and desktops that allows for free instant messaging and calling, aggregating accounts such as SKYPE and Facebook, among other social networks.

3 Refugees in Dadaab, as elsewhere under UNHCR mandates, can work for humanitarian aid and development agencies and be reimbursed through a stipend referred to as 'incentive wages'. These funds are significantly less than what Kenyan nationals working in comparable positions are paid in the same location, within the same agency.

${ }^{4}$ The Tripartite Commission for the Voluntary Repatriation of Somali Refugees is focused on supporting the voluntary repatriation of Somali refugees to Somali (UNHCR, 2016). 